\title{
Introduction: Revisiting Aboriginal Social Organisation
}

\author{
Patrick McConvell
}

This volume presents papers written about Aboriginal Australia for the AustKin project. By way of definition, 'kin' refers to kinship terminology and systems, and related matters of marriage and other behaviour; and 'skin' refers to what is also known as 'social categories' and what earlier anthropologists (e.g. Fison \& Howitt 1880) called 'social organisation': moieties, sections, subsections and other similar categories. Kinship terms are 'egocentric' in anthropological parlance and skin terms are 'sociocentric'. Different kinship terms are used depending on the ego (propositus) and who is being referred to. Conversely, skin terms are a property of the person being referred to and the category to which he or she belongsnot of their relationship to someone else. However, membership of a skin category does imply a kinship relationship. For example, I was assigned the skin (subsection) name Jampijina by the Gurindji, which means that I am classified as brother (kinship term papa) to other people of Jampijina skin, father to Jangala and Nangala, and so on.

Additionally, a 'clan', known as a 'local descent group', is a group rather than a category such as a skin. Namely, it is a group of people who have common rights and interests in property, which may be intellectual property or, importantly, tracts of land. These rights and interests are generally inherited by descent, from fathers and/or mothers and more distant ancestors (although rights can be transmitted in other ways). 
By contrast, people of a skin category are not collective owners of anything: for example, the people of the Jampijina subsection do not have common rights and interests in land. However, there are important connections between 'local organisation' (clan) systems, 'social organisation' (skin) systems (Fison \& Howitt 1880) and kinship. This volume aims to distinguish between these three systems and to investigate the connections between them.

Those who have studied the kinship and social organisation systems of Indigenous Australians have been equally astounded by their crystalline beauty and frustrated by their impenetrable complexity. Significantly, those impressed by the mathematical elegance of Indigenous kinship and social organisation systems are often viewing them through the prism of social category systems (skins), such as moieties, sections and subsections. Such social categories abstract away from a complex reality to a more idealised pattern. The more complex of these categorisations are unique to Australia (the eight subsections) or nearly so (the four sections). This strengthens the impression that in Australia we are in the presence of something very special, perhaps even primordial.

In this volume, we bring together papers that deal with the phenomena in a less awe-struck frame of mind and look for patterns of relationship and origin in the variation that we see. Nevertheless, what we are witnessing is indeed a monumental achievement in the social realm of a hugely creative group of cultures on the Australian continent. These cultures have been on the move, creating new solutions to problems of social organisation, rather than merely reproducing a template that was established 50,000 years ago. This volume presents the latest findings on Australian Aboriginal kinship systems and explores the extraordinary constellations of kinship terminologies and social category systems across the continent that are unique to Australia. The recent revival of kinship studies has allowed scholars the fresh advantage of technological and methodological innovations in the field. Systematic comparative approaches-inspired by reconstructive methods in historical linguistics—-have combined with database-driven analysis to reopen old questions and generate new ones. Within this volume, panoramic modelling of kinship prehistory and diffusions of terms and systems are set alongside detailed investigations of specific models of social organisation.

Today, the study of Australian kinship is far less ambitious in its aims than it was in the nineteenth century, when field research held forth the promise of unifying biological and social sciences, unlocking the enigma 
of global prehistory and ultimately validating European claims of cultural supremacy (see Chapter 2 for an overview). However, while nineteenthcentury scholars foundered in their misguided efforts to reconcile Australian social organisation with the reigning ideologies of the day, the preliminary questions they grappled with remain relevant almost 150 years after they were first posed. The type and distribution of Australian kinship systems, their patterns of diffusion and change over time, and traditional relationships of descent and land tenure are still issues requiring urgent intellectual attention.

The revival of interest in kinship studies, both in Australia and elsewhere, has permitted a reassessment of old questions using new methodological tools. For example, in the AustKin project, linguists and anthropologists are in a position for the first time to address two unresolved questions: How did the unique social category systems found in Aboriginal Australia originate? Further, what has been their relationship with kinship and marriage systems over time?

As Morgan (1997) recognised in 1871, reliable analysis of kinship data can only be performed when the evidence is collected in the language of the informant. He also emphasised the importance of collecting all kinship terms in a given language with a large number of the kin types that constituted their meanings, so that a clear picture of the type of operating kinship system could emerge. This methodological principle was adopted by AustKin, although (as with Fison and Howitt's 1880 correspondents' lists) the kinship term lists available did not always live up to this requirement.

By accurately associating sets of terms with languages, AustKin also opens up the possibility of comparative etymological reconstruction, allowing researchers to deduce whether kinship terms have been inherited from ancestral languages or borrowed from neighbouring groups. Earlier work has clearly shown how important linguistic evidence is to plotting the development and spread of social systems. The gender prefixes in subsection terms of a genderless language such as Warlpiri (masculine Japanangka vs feminine Napanangka) can be explained by tracing the terms to languages far to the north that earlier had gender prefixes of the right form (McConvell 1985). In short, historical changes to systems of social organisation can often be inferred by examining linguistic phylogeny and patterns of diffusion. 
While anthropological (ethnological) research on kinship has sometimes been comparative, thus producing synchronic typologies of systems, it has rarely focused on diachronic change and reconstruction. Even the earlier work on transformations by Lévi-Strauss (1969) and the more recent significant work of Godelier et al. (1998) have not tied transformations to times, places and lexical forms. In linguistics, however, there has been a current of research on reconstructing kinship terms and systems (e.g. Blust 1980; Whistler 1980), but not within an Australian context. The aim of the AustKin project has been to apply the comparative method in linguistics to Australian kinship data using systematic querying of databases and to marry the results to anthropological work.

The AustKin II database was the second phase of the AustKin project, which went online in 2013. It is linked to the AustKin I but is able to store, handle and map two additional features of kinship and social organisation: 1) marriage rules, including aspects of prescription, proscription (unmarriageability), preferential and alternative marriages; and 2) category systems such as moieties, semi-moieties, sections and subsections. The aim is to track and visualise how these systems interact with each other over time.

Earlier attempts at typologies of kinship systems often included marriage rules in the definition of kinship systems. This would not be a wise precedent for the AustKin project to follow because we know that sometimes marriage systems do not fit exactly within the kinship terminologies. Due to AustKin's concern with change, we also need to record cases of lack of fit very carefully, as they may represent 'phasing in' of a kinship terminology and marriage system that are not completely harmonious with each other due to time lag or competition between different systems exerting influence on a group. It is important to record marriage rules separately from kinship systems and to compare them as independent factors.

Sections and subsections and their development are topics that have been investigated by two leaders of the AustKin project over the years, including the spread of sections in the Western Desert (Dousset 2005), and the origin and spread of subsections in north central Australia (McConvell 1985, 1997). Sections and subsections are sociocentric divisions, four and eight respectively. Each occurs in separate regions with a little overlap between them. The sections are made up of a set of classificatory or fictive parallel kin of the same or harmonic $(+2$ or -2$)$ 
generations. Subsections are divided into two, with those who are classificatory mother's mother (or mother's mother's siblings) and woman's daughter's children to each other separated into a different subsection from siblings and father's father (or father's father's siblings). They are categories that each individual derives from his or her parents; however, the section or subsection term of the child is different from his or her parents. Subsections are unique to Australia, and sections nearly sothere are sections in Panoan-speaking groups in South America.

Unlike kinship terms, which tend to be mostly inherited, subsection terms, and probably most section terms, are diffused (loan words). It seems unlikely that kinship terminologies and social categories (skins) have parallel histories. More complex relationships are being uncovered in this project.

In relation to Australia, there has been a tradition of combining kinship terminology, marriage rules and social categories (sections and subsections) into a unitary 'kinship system' in which these elements are inextricably connected by close functional cohesion. This perception of how Australian systems operate became especially influential due to analyses of section systems by anthropologists exploring componential approaches (e.g. Burling 1962). Often, this neglects the relative independence and differing histories of these elements. More significantly for the project, this approach does not facilitate comparison and the tracing of diachronic interactions of kinship terminology, marriage and social categories that have been identified as major goals.

Beyond these three components, there is also a demographic component: in particular, how marriage patterns relate to the maintenance and transformation of marriage rules, kinship systems and social categories. The possibility of 'bottlenecks' leading to changes in social category systems relates to marriage patterns, general interaction and perhaps population size and density.

A number of writers have proposed hypotheses that relate different social categories to differing ecological conditions (e.g. McKnight 1981; cf. Yengoyan 1976). Ecological determinist hypotheses generally do not work well and are flawed in their synchronic and ahistorical nature-what is needed is an understanding of the movements that drive the diffusion of such systems. 
Hypotheses such as those of Keen $(1982,2004)$ that link polygyny to types of marriage and associated age structure and marriage network flows in different areas of Arnhem Land are more promising. The work done in AustKin I in developing a diachronic dimension for Yolngu kinship in north-east Arnhem Land (McConvell \& Keen 2011) can now be merged with the correlational work by Keen to explore the dynamics of how kinship, marriage and demography influence each other over time.

Another wideranging hypothesis to which we pay attention is that of White and Denham (2007), who stated that the functional advantage of kinship systems such as Omaha skewing and social categories such as sections and subsections, lies in their driving force towards exogamy, rescuing small groups from otherwise almost-certain demographic collapse. Simulations could play a role in testing these types of hypotheses.

If the historical reconstruction work in AustKin can find relative or even absolute dates for these institutional changes, we will be able to contribute to a debate that has gone on for some time over whether the society of recent times in Australia is very ancient or if there was a major change, perhaps related to 'intensification' (economic and population growth), identified by archaeologists in the Holocene. It has been argued that this has led to more stable groupings and ethnicities, based on specific types of kinship, marriage and social organisation.

The hypothesis of the origin and spread of subsections now has a secure foundation; however, it still requires more detailed work, which is shown in Chapters 9 and 10. The question of the origin of sections, the older system from which subsections evolved through a merger of two section systems, is still at a more preliminary stage; however, McConvell presents some hypotheses in this volume.

The study of the evolution of Australian kinship systems and their relationship to marriage and social category (skins) systems is not only significant to Australia. Allen (1998) has claimed that the primordial world social organisation was based on a 'tetradic' structure, similar to the sections from which Dravidian-Kariera systems evolved. Hage (2003) has also claimed to have found Kariera systems in protolanguages in many parts of the world.

If the earliest kinship systems we can detect in Australia through our reconstruction methods are Kariera, then this adds some weight to the world primordial (or very early) Dravidian-Kariera hypothesis. However, 
this is by no means conclusive, as we are likely dealing with protolanguages that are not much more than 5,000 years old. A similar problem of relative short age also besets the idea that Australian sections may be relics of a very early human type of social organisation. It may be that sections are in fact younger than the protolanguages (e.g. Proto-Pama-Nyungan) and this is something AustKin may be able to find out. In order to provide credible answers to these questions, we should not indulge in speculation. There are good linguistic and ethnological methods on hand and these need to be applied systematically.

Further, the question of the relationship between kinship, marriage and other aspects of Indigenous social organisation, such as social categories and descent, is now even more relevant due to native title (see Finlayson et al. 1999; Sutton 2003). For instance, the notion of a body of law and custom belonging to an Indigenous society assumes some common strands that link the different elements. Conversely, it also allows for historical change that may alter the relationship between these elements. The current relevance of the study of kin, skin and clan is highlighted in several chapters in this volume.

\section{The Chapters in This Volume}

\section{Evolving Perspectives on Aboriginal Social Organisation: From Mutual Misrecognition to the Kinship Renaissance}

In Chapter 2, Piers Kelly and Patrick McConvell provide background on the intellectual history of how Australian Aboriginal social organisation has been perceived by outside observers. Many of the early observers evinced little understanding of or interest in Australian Aboriginal social organisation; however, as European scholars began to adopt social evolutionism, Australia captured imaginations as exemplifying the 'most primitive' forms of social life. The chapter then moves on to the twentieth century when anthropology mainly cast aside evolutionism in favour of synchronic ethnography, led in Australia by Radcliffe-Brown. Structuralist anthropology gave rise to comparative typology, as in the work of Radcliffe-Brown, Lévi-Strauss and Scheffler; however, direct historical or evolutionary models remained rare, only recently re-emerging as part of the 'renaissance of kinship'. 


\section{Systems in Geography or Geography of Systems? Attempts to Represent Spatial Distributions of Australian Social Organisation}

In Chapter 3, Laurent Dousset proposes that 'social organisation', as defined by Fison and Howitt (1880), of social categories played a significant role alongside 'local organisation', clans and phratries in map-making. 'Social organisation' forms were taken to suggest forms of governance arranged in a historical sequence. Varieties of Australian social organisation are shown on a map generated by AustKin, with moieties, sections, subsections and semi-moieties represented.

The mapping of Australian society is discussed in terms of three periods in the history of the mapping of Indigenous Australia: homogenisation period, organic period and dynamic period. In the homogenisation period, the map of social organisation is one that reflects the history of migration, with more 'modern' tribes progressively imposing themselves onto the sociocultural landscape. In introducing the organic period, Dousset looks at two innovators who departed from the migration-social evolution model in the twentieth century: Davidson, who proposed a geographical approach to social institutions and (naturally) used maps a great deal; and Radcliffe-Brown, who ushered in the structuralist-functionalist rejection of any historical explanations. From his earliest mappings in the Pilbara, Radcliffe-Brown attempted to integrate local and social organisation and gave a geographical basis to sections that was contrary to the reality. The dynamic period in the late twentieth century began with a recognition of the problems of map-making, leading to hesitation about drawing lines on maps and demanding a clear exposition of territoriality in Australia due to land rights and native title cases. At the same time, an awareness of change and the movement of social organisation systems began to appear in maps, hence the name 'dynamic' period.

\section{The Sources of Confusion over Social and Territorial Organisation in Western Victoria}

In Chapter 4, Raymond Madden takes a further look at the distinction between 'local' and 'social' organisation that perhaps had not been made clear enough by Fison and Howitt (1880), subsequently leading to some confusion. In the case highlighted by Madden, this confusion has had serious consequences in the native title era, with some people (including 
Indigenous Australians) reading the situation as matrilineal inheritance of rights in land—an interpretation that is not justified according to Madden. The chapter's focus is on western Victoria and it homes in on what the early sources on the region, mainly Dawson (1881) and Howitt (1904), had to say about territorial (local) organisation. Dawson (1881) named the local territorial group the 'family', which is ostensibly equivalent to what others have called the 'clan' or 'estate group', recruited primarily by patrifiliation. Howitt (1904) listed three levels of groups associated with hierarchically organised land: 'nations', the cultural blocs of dialect groups; 'tribes', the dialect groups; and 'clans' or 'hordes', the local estate group at the bottom of the hierarchy. The latter two are distinguished by line of descent: 'clan', patrilineal; and 'horde', matrilineal. This formulation turned out to be a major source of confusion, as it was based on whether the area had patrimoieties or matrimoieties.

The second part of the chapter is devoted to change as a result of the colonisation of Victoria in the early nineteenth century. The severe impact on the Indigenous population brought demographic collapse and the concentration of remnants around missions. In turn, this brought about changes in how Aboriginal people thought about their affiliations to land, with the distinct local patrifilial clan identities being replaced by larger conglomerates that were based on cognatic (not lineal) ties. Now, many Aboriginal people in western Victoria believe that their traditional descent and land tenure system was matrilineal, and writers in recent times have also contributed to this perception. It is important in the native title era to understand the history of local and social organisation in the context of colonial history, so that neither the poles of continuity nor destruction of traditional society is unduly emphasised.

\section{Disputation, Kinship and Land Tenure in Western Arnhem Land}

In Chapter 5, Mark Harvey moves the scene to the north of Australia. He continues on the topic of land tenure but also addresses the subject of kinship. The theme of interpersonal interaction in the form of disputation and how this affects variation of kinship term usage is also new in this volume.

The chapter begins with the assertion that disputation is more prominent in discussion of marriage than of land tenure. Similar to Madden's discussion in the context of western Victoria, population collapse followed 
European incursion in northern Kakadu in the late nineteenth and early twentieth century. According to Berndt and Berndt (1970), disputes between and about marriage partners often hinged on whether they were gagali (prescribed marriage partners) or kanjok (a broader category of cross-cousins and less favoured as spouses). Another cause of shame and dispute was when a betrothal was not organised early and lapsed, and the cross-cousin relationship instead became one of 'father-daughter'.

Harvey then moves on to land tenure. Apart from language group names at the highest level, the main terminologies are Gunmogurrgurr names and the Yigurumu exclamation referring to areas of land. Harvey links this situation to the lack of public debate about these matters, which is in contrast to the greater public airing of disagreements about kinship and marriage.

In the final section, Harvey reveals evidence, including placenames, that the discontinuous and fragmented nature of estates was in fact an artefact of the colonial history: estates were originally continuous.

\section{Moiety Names in South-Eastern Australia: Distribution and Reconstructed History}

In Chapter 6, Harold Koch, Piers Kelly and Luise Hercus deal with the moiety systems of south-eastern Australia, south of the region where section systems were found-although moieties existed in these areas as well. Evidence is carefully sifted through to arrive at accurate descriptions and forms of nomenclature. Further, historical linguistics and ethnology are used to reconstruct the history and etymology of moieties in the region. One conclusion (as other chapters conclude for other social categories) is that moieties spread by cultural diffusion after the time of the protolanguages of subgroups, and not along with the languages as they expanded. Although the authors do not attempt to date these spreads, it is presumed that they must be relatively recent, occurring within the last millennium or two.

Six areas are presented across South Australia, Victoria, the Darling and south-west Queensland, each with its own distinctive pair of moiety terms. Five areas have matrimoieties, with only central Victoria having patrimoieties. 
The chapter then reviews earlier attempts at mapping social category naming systems and explores correlations and mismatches within linguistic subgroups. The area around the Darling and Murray rivers is a good candidate for the origin of moiety systems, with the known occurrence of large multiethnic ceremonies in the region presenting as a possible vector of diffusion.

In the final section on etymology of moiety terms, which takes a wider view across eastern Australia, the animal terms that are used in various areas are discussed, with comments made regarding the distinctive features of the two emblematic species, such as body shape, fur versus scales, and habitat. Other aspects that enter into the dichotomies are shade, wind and seasons; however, no overall conclusions about origins are reached.

\section{Patriclan Subsets of the Ashburton River District in Western Australia}

In Chapter 7, Peter Sutton discusses 'patriclan subsets', an institution otherwise known as patriphratries, which are named combinations of clans into sets-usually around four. They are quite similar in structure (although not in the form of names) to the patriphratries that are more well known in south-western Australia that have been found as matriphratries in adjacent areas and analysed as semi-moieties due to the reported marriage and filiation rules between them. No such rules have been reported for the Ashburton systems that have been labelled as 'totem classes'. Structurally, they sit somewhere between social categories and local descent groups and would require further study as a possible ancient type of institution. The main source of information on the Ashburton phratries comes from the work of Daisy Bates' fieldnotes (n.d.), which Sutton draws on in this chapter, as well as Radcliffe-Brown's fieldwork and the more recent linguistic work of Austin.

One characteristic of this system that aligns with social categories such as sections is that the named categories are not confined to a single language group but are used over a wide area. Sutton suggests that they are 'counterterritorial', transcending local organisation. They are not exogamous like many non-local matriclans and matriphratries, but do have a tendency towards endogamy. 
Sutton compares the phratries of the Ashburton with the mala grouping of clans of the north-east Arnhem Land Yolngu, referred to as 'phratries' by Warner (1937), a naming not followed by other anthropologists of the region.

Sutton goes on to discuss marriage and the relationship between phratries and sections. He concludes that 'this system and its associated social etiquette shared several of the key features of universalist kin superclass systems while at the same time being rooted in patrifilial localism'; however, in situating the system as straddling both local and social organisation, he is careful not to imply that this is part of a transition from one to the other.

\section{The Birds and the Bees: The Origin of Sections in Queensland}

In Chapter 8, Patrick McConvell looks at sections, the fascinating system of four named sociocentric divisions based on kinship and ideal marriage rules. At its high-water mark, after the full impact of colonial onslaught was felt, sections were in use and transmitted over approximately half the area of Australia. The other major system also expanding in this period was subsections, in the middle of the section distribution in the central north of the continent, with sections to the east, west and south. The focus of the chapter is on how sections could have formed from pre-existing social categories, moieties or phratries. A number of speculative solutions have been proposed, most referring to the fact that a combination of matrimoieties and patrimoieties with some adjustment of marriage could logically produce sections.

The issue for McConvell is whether these suppositions have merit. He examines situations in north Queensland in which there are signs of transitions to sections and finds that evidence of combinations of matrimoieties with patrimoieties is absent. Rather, what seems to have occurred is the interaction of two neighbouring patrimoiety systems, with moiety names referring to two kinds of eagle and bee, in which a modified marriage alliance between the groups led to sections.

One of these nascent section systems (here named 'Queensland General' [QG]) spread across a vast area of interior Queensland with closely similar terms, indicating a rapid and relatively recent spread, probably in the last millennium or two. The distribution of this QG system is 
similar to that of the Maric subgroup of languages that rapidly spread across interior Queensland in the late Holocene. This tempts an analyst to regard the section system as being carried by the Maric languages, as they split up and spread out, through inheritance. However, linguistic evidence suggests that the section spread did not accompany the breakup of the Maric languages, but rather the sections spread by diffusion after the languages had already expanded, and not from the same origin point or in the same direction.

In north Queensland, tentatively proposed here as the origin area of sections, we cannot use the similarity of forms of terms as a guide to the reconstruction of history of sections as a whole because the forms in different regions are unrelated. This leads us to take a closer look at one of the modes of diffusion of nomenclature identified for south-eastern Australia by Koch et al. (see Chapter 6): 'calquing' or 'loan translation'.

The final part of this chapter takes a broader perspective regarding the question of sections. There is only one system outside of Australia that almost completely matches the Australian system: the Panoan system between the Andes and the Amazon in South America. Not all Panoanspeaking groups have sections but a number of groups have patrimoieties, patriphratries and patriclans that may have played a role in the origin of sections. Linguistic evidence suggests that sections are not old, perhaps one thousand years old or less. The names of sections and moieties are transparently those of animals that have symbolic roles.

\section{Generic Terms for Subsections ('Skins') in Australia: Sources and Semantic Networks}

In Chapter 9, Patrick McConvell and Maïa Ponsonnet look at social categories and local organisations that have generic names that are roughly equivalent to 'moiety', 'section', 'subsection', 'clan' and so on. The adoption of other-presumably previous - generic names from other social categories as the term for 'subsection' is one of the points covered in this chapter. However, more significant is the range of terms for subsections drawn from other semantic fields. In the case of ngurlu, used for both 'matriclan' and 'subsection' in the Victoria River District of the Northern Territory, this is a word in Gurindji for 'flavour' and it has a range of associated meanings; it is also the term for 'seed' in a number of related languages. Source meanings of generic terms for subsections are 
split up into several main sets: 1) dermis (skin of body); 2) smell, flavour and associated senses; 3) body; 4) head and associated attributes; 5) name; and 6) time, country and associated senses.

The fact that dermis is only found in the languages of the Cobourg Peninsula in western Arnhem Land is part of the evidence that this is the area from which the generic term 'skin' in Pidgin English originated. This is supported by historical evidence from the British early settlements at Port Essington.

Some regions use terms for body or sweat odour for generic subsections. This connection between a person's smell and their essence and identity is a common conceptual link in Australia. 'Body' is also commonly colexified with 'person' but less commonly with 'subsection', and rarely it seems are all three found together represented by one word.

The method of 'semantic mapping', specifically used by Alex François, is utilised in this study to show connections in the other meanings of the terms for 'subsection'. Although semantic maps are not necessarily geographical, the divisions between different meanings of terms for 'subsection' do largely mirror geographical regions. Similarly, semantic maps are not normally used in reconstruction of historical change; however, in this chapter they are harnessed to assist in plotting these changes in conjunction with what we already know about the origin and spread of subsections.

\section{The Development of Arandic Subsection Names in Time and Space}

The history of the origin and diffusion of subsections is now firmly grounded in McConvell's (1985) hypothesis, with earlier ideas now generally sidelined as highly speculative and flawed. However, among those who accept the main lines of McConvell's (1985) hypothesis, there are also differences of opinion regarding the detail and chronology based on linguistic evidence. One site of difference has been the historical interpretation of the form of subsection (and section) terms in the Arandic group of languages in Central Australia, which Harold Koch discusses in Chapter 10. 
McConvell's (1985) hypothesis proposes that subsections arose from a particular kind of merger of two four-section systems in the region around Katherine (from the west and north) in the Northern Territory that was followed by the diffusion of varieties of the new system to the west, south and east.

McConvell $(1985$, pp. 6, 10) pointed out that the Set 1 of subsections (A1, B1, C1 and D1) are related in form to the western section terms respectively (A, B, C and D) and that they are also closely similar to the section terms in southern Arandic languages that only have section terms. Koch reviews different hypotheses proposed regarding the historical sequence that might have led to this pattern, including the suggestion that there were two successive spreads from the north: first sections, then subsections. Spencer and Gillen (1969 [1899]) and Elkin (1939-40) reported that the Arrernte said that they had received the subsections from northern groups in recent historical times. Koch's interpretation (which differs from McConvell 1985) is that the addition of gender prefixes $j a$ - (masculine) and na- (feminine) initially applied to sections, and it was these that spread south first and underwent the full initial syllable dropping that occurs in Arandic (e.g. Japanangka $>$ Penangke). Later, the eight subsections with prefixes diffused south from the group referred to by Spencer and Gillen (1969 [1899]) as 'Ilpirra'-often interpreted as 'Warlpiri', but actually, as Koch shows, 'Anmatyerre'. This scenario, if confirmed, also provides evidence of the previous existence of western sections in the northern savanna belt before the genesis and spread of subsections.

\section{Close-Distant: An Essential Dichotomy in Australian Kinship}

Close versus distant relatives is a commonplace expression in European kinship that refers to physical distance, genealogical distance and how frequently and intimately relatives interact. In Chapter 11, Tony Jefferies aims to show that a similar dichotomy is important in the understanding of how Australian Indigenous kinship systems work. According to Jefferies, this has not been fully recognised in the anthropological literature, even though Aboriginal people have been recorded talking about it from the early days of contact, and he argues that it is a central emic concept in their understanding. 
The chapter includes an account of various anthropologists who have referred to close-distant in Australia, such as the requirement that a bride be both geographically and genealogically distant from the husband.

In the Western Desert, geographical distance is the key in marriage choices and different terminology is used for close and distant cousins. Dousset (2005) is cited as providing the best description of this, and other ethnographic examples are also presented.

\section{Asymmetrical Distinctions in Waanyi Kin Terminology}

The Waanyi language traditionally straddled the Queensland - Northern Territory border to the south of the Gulf of Carpentaria. In Chapter 12, Mary Laughren begins with a detailed description of the meanings and forms of Waanyi kinship terms, explaining when there is a distinction in kinship terms between brother and sister relations and when there is no such gender-based distinction. There are also differences between junior and senior terms in harmonic generations, and instances when one term is applicable for both. These two types of distinctions are called asymmetrical and symmetrical for gender and generation respectively.

This chapter focuses on how these differences in symmetry can be explained. The hypothesis is that asymmetry is related to the marriage alliance and wife bestowal system. However, this is not necessarily a consequence of that type of alliance and bestowal, since the Warlpiri also has this type of system but does not distinguish gender in kinship terms. In relation to generation asymmetry, it is shown in a number of languages in the region that Waanyi patterns conform to an areal type.

One conclusion reached is that 'the marking of both sex and generationlevel distinctions in FM and MM class terms is a shared feature of the languages of the southern Gulf of Carpentaria region. Waanyi has borrowed terms from neighbouring southern Warluwarric languages in order to lexify distinctions probably not made in Proto-Garrwan'. The pattern of terms in Waanyi and neighbouring languages reflects areal multilingualism and joint participation in ceremonies and marriage networks. 


\section{Genesis of the Trinity: The Convergent Evolution of Trirelational Kinterms}

Trirelational kinship terms are a fascinating complexification found in a number of areas of Northern Australia. Since these systems are not usually found by elicitation or superficial fieldwork, they may well have had a wider distribution, but were not discovered before the systems or the languages were lost. On a global scale, they have been recorded in one part of the Amazon; however, the same comments apply: perhaps they were missed elsewhere.

Kinship terms in most languages refer to the relationship between the propositus (anchor or pivot) and the referent. Therefore, if I talk about 'John's father', it is the relationship between John and the referent that fully covers the term 'father'. Whatever relationship exists between 'me', the speaker, and the propositus or referent is not encoded in the kinship term. With a trirelational system it is different: the relationship between me and the propositus and referent is also encoded.

In Chapter 13, Joe Blythe reports not on an established and elaborated system, but a trirelational system in the first throes of birth in the Murrinhpatha language of the Wadeye area of the Northern Territory. The mechanism of its genesis, as far as we can tell, is different from that of other trirelational systems; however, its functional properties are parallel, showing that this is an option that is inherent in the way kinship systems are constituted-but one that is only rarely developed. Blythe applies the notion of 'convergent evolution'-namely, that these trirelational systems arise from similar functional motivations. Whether the common functional motivations he identifies in the need to classify referents in discourse hedged by restrictions and in-group knowledge is sure to be the subject matter of further debate.

The key evidence in this chapter is the lexicalisation of phrases to form trirelational terms and great use is made of historical documentation of this process at an earlier stage, as well as around five hours of transcript of contemporary Murrinhpatha conversation. This provides solid evidence of the interactional pragmatics of kinship and explications by participants.

The next part sets this in the context of historical work on the Murrinhpatha by Stanner (1936) and Falkenberg (1962). This body of work was somewhat unusual compared with the ethnography from 
that period because it posited a change in progress in the kinship system - a supposition that Blythe reveals as unjustified. However, despite the recording of trirelational terms by Stanner (1936), he did not understand its significance or how it provided an elaboration of kinship that was different from the change he was imagining.

A section follows that cites passages in which participants in conversation use such ' $\mathrm{X}$ says TERM to $\mathrm{Y}$ ' formulas to disambiguate reference and relationships.

One of the conclusions of the chapter is that the emergence of Murrinhpatha trirelational terms is part of a pattern of solutions for usage-based constraints on person reference items. The chapter includes a useful survey and map of trirelational terms across Australia, and a supplement on interaction in discourse.

\section{References}

Allen, N 1998, 'The prehistory of Dravidian-type terminologies', in M Godelier et al. (eds), Transformations of kinship, Washington DC: Smithsonian, pp. 314-31.

Bates, D n.d., Manuscripts and papers of Daisy Bates (MS 365 and MS 2300), Canberra: National Library of Australia.

Berndt, R \& Berndt, C 1970, Man, land and myth in north Australia: the Gunwinggu people, Sydney: Ure Smith.

Blust, R 1980, 'Early Austronesian social organization: the evidence of language', Current Anthropology, 21(2), pp. 205-47. doi.org/ $10.1086 / 202430$.

Burling, R 1962, 'A structural restatement of Njamal kinship terminology', Man, 62(201), pp. 122-4. doi.org/10.2307/2797628.

Dawson, J 1881, The Australian Aborigines: the languages and customs of several tribes in the Western District of Victoria, Australia, Melbourne: George Robertson (Facsimile edition, 1981, Canberra: AIAS).

Dousset, L 2005, Assimilating identities: social networks and the diffusion of sections, Sydney: Oceania Publications, Monograph 57. 
Elkin, AP 1939-40, 'Kinship in South Australia', Oceania, 10, pp. 196-234.

Falkenberg, J 1962, Kin and totem: group relations of Australian Aborigines in the Port Keats district, Oslo: Oslo University Press.

Finlayson, J, Rigsby, B \& Bek, HJ (eds) 1999, Connections in native title: genealogies, kinship and groups, Canberra: Centre for Aboriginal Economic Policy Research, Research Monograph 13.

Fison, L \& Howitt, AW 1880, Kamilaroi and Kurnai, Melbourne: George Robertson.

Godelier, M, Trautmann, T \& Tjon Sie Fat, F (eds) 1998, Transformations of kinship, Washington DC: Smithsonian.

Hage, P 2003, 'The ancient Maya kinship system', Journal of Anthropological Research, 59(1), pp. 5-21.

Howitt, AW 1904, The native tribes of south-east Australia, London: Macmillan \& Co. (Facsimile edition, 1996, Canberra: Aboriginal Studies Press).

Keen, I 1982, 'How some Murngin men marry ten wives: the marital implications of matrilateral cross-cousin structures', Journal of the Royal Anthropological Institute, 17(4), pp. 620-42.

Keen, I 2004, Aboriginal economy and society: Australia at the threshold of colonisation, Melbourne: Oxford University Press.

Lévi-Strauss, C 1969, The Elementary structures of kinship, Boston: Beacon Press (translation of Les Structures Élémentaires de la Parenté, 1949).

McConvell, P 1985, 'The origin of subsections in Northern Australia', Oceania, 56, pp. 1-33.

McConvell, P 1997, 'Long lost relations: Pama-Nyungan and northern kinship', in P McConvell \& N Evans (eds), Archaeology and linguistics: Aboriginal Australia in global perspective, Melbourne: Oxford University Press, pp. 207-36. 
McConvell, P \& Keen, I 2011, 'The transition from Kariera to an asymmetrical system: Cape York Peninsula to north-east Arnhem Land', in D Jones \& B Milicic (eds), Kinship, language and prehistory: Per Hage and the Renaissance in kinship studies, Salt Lake City: University of Utah Press, pp. 99-132.

McKnight, D 1981, 'Distribution of Australian Aboriginal "marriage classes": environmental and demographic influences', Man (n.s.), 16(1), pp. 75-89.

Morgan, LH 1997, Systems of consanguinity and affinity of the human family, Lincoln: University of Nebraska Press. (Smithsonian Institution, vol. 17, 1871.)

Spencer, B \& Gillen, FJ 1969 [1899], The native tribes of Central Australia, Oosterhout, Netherlands: Anthropological Publications [Reprinted from 1899 edition by Macmillan \& Co].

Stanner, WEH 1936, 'Murinbata kinship and totemism', Oceania, 7 , pp. 186-216.

Sutton, P 2003, Native title in Australia: an ethnographic perspective, Cambridge: Cambridge University Press. doi.org/10.1017/CBO97 80511481635 .

Warner, WL 1937, A black civilization: a social study of an Australian tribe, New York: Harper.

Whistler, K 1980, Proto-Wintun Kin Classification: a case study of reconstruction of a complex semantic system, $\mathrm{PhD}$ dissertation, University of California, Berkeley.

White, D \& Denham, W 2007, 'The Indigenous marriage paradox', SASci meeting, San Antonio.

Yengoyan, A 1976, 'Structure, event and ecology in Aboriginal Australia: a comparative viewpoint', in N Peterson (ed.), Tribes and boundaries in Australia, Canberra: Australian Institute of Aboriginal Studies, pp. 121-40. 
This text is taken from Skin, Kin and Clan: The dynamics of social categories in Indigenous Australia, edited by Patrick McConvell, Piers Kelly and Sébastien Lacrampe, published 2018 by ANU Press, The Australian National University, Canberra, Australia.

doi.org/10.22459/SKC.04.2018.01 